\title{
Aggregation of Polypeptide-Based Amphiphiles in Water
}

\author{
Tomokiyo DoI, Takatoshi KInOshita, Hiroki KamIYA, Shintaro WASHIzU, ${ }^{*}$ \\ Yoshiharu TsUJITA, and Hiroaki YoshIMIZU \\ Department of Materials Science and Engineering, Nagoya Institute of Technology, \\ Gokiso-cho, Showa-ku, Nagoya 466-8555, Japan \\ * Fujinomiya Research Laboratories, Fuji Photo Film Co., Ltd., Fujinomiya, Shizuoka \\ 418-8666, Japan
}

(Received September 4, 2000; Accepted November 14, 2000)

\begin{abstract}
The amphiphile, poly ( $\gamma$-methyl L-glutamate) with a phosphate head group at the terminal (PMG - $_{10}$ ) was prepared. $\mathrm{PMG}_{10}-\mathrm{P}$ was dispersed in aqueous solution to form a globular assembly after sonication. One hour later, globular assemblies had joined each other to transform into fibrous aggregates. At $24 \mathrm{~h}$, the fibrils assembled to form twisted ribbon-like aggregate. The thickness of the ribbon-like sheet was ca. $4.0 \mathrm{~nm}$ which is compatible with the chain length of $\mathrm{PMG}_{10}-\mathrm{P}$ when in the $\beta$-form conformation. The $\beta$-form conformation of $\mathrm{PMG}_{10}-\mathrm{P}$ was confirmed by circular dichroism and fourier transform infrared spectrometry (FT-IR) measurements. The ribbon-like aggregate is $\beta_{\mathrm{I}}$ at room temperature. The phase transition from $\beta_{\mathrm{I}}$ to $\beta_{\mathrm{II}}$ above $c a .35^{\circ} \mathrm{C}$ was confirmed by differential scanning calorimetry (DSC) measurements. Further increase in temperature induced the disaggregation of $\mathrm{PMG}_{10}-\mathrm{P}$ whose conformation is in random coil with some $\alpha$-helix. This conformational behavior is summarized in a temperature-concentration phase diagram.
\end{abstract}

KEY WORDS Amphiphilic Polypeptide / Ribbon-Like Molecular Assembly / $\beta$-Form / Phase Transition / Temperature Concentration Diagram/

In the organization of a cell, the lipid bilayer is a very important structure. ${ }^{1}$ The double layer structure composed of lipid molecule formes spontaneously in water. ${ }^{2}$ Kunitake et al. demonstrated the formation of a synthetic bilayer membrane and vesicle constructed with didodecyldimethylammonium bromide ${ }^{3}$ with similar characteristics to lipid bilayers. Their discovery led to studies on molecular assemblies and various of artificial amphiphilic molecules have been prepared..$^{4-17}$ These molecules form not only bilayer structures comparable to the lipid bilayer but also another superstructures in water. ${ }^{4-13}$ A synthetic amphiphile containing an amino acid residue aggregates to form the helical and/or cylindrical structure. ${ }^{4-17}$ These structures are well-defined. The interior of assembly may be rather statistical, because these assemblies are composed by amphiphiles containing hydrocarbons as a hydrophobic part. There are a few studies on amphiphiles consisting of nonhydrocarbon tails. ${ }^{18-25}$ In order to construct a molecular assembly having well-defined structure, peptide derivatives may be a useful.

In this study, we prepared an amphiphile, $\operatorname{poly}(\gamma$-methyl L-glutamate) with a phosphate head group at the terminal $\left(\mathrm{PMG}_{10}-\mathrm{P}\right)$, containing polypeptide as the hydrophobic part instead of hydrocarbons and studied aggregation in aqueous solution and also temperature and concentration effects on $\mathrm{PMG}_{10}-\mathrm{P}$ aggregates.

\section{EXPERIMENTAL}

\section{Sample Preparation}

The amphiphile, $\operatorname{poly}(\gamma$-methyl L-glutamate) with a phosphate moiety at the terminal (PMGn-P; Scheme 1), was obtained by the polymerization of the $N$-carboxy anhydride of L-glutamic acid $\gamma$-methyl ester (MG-NCA) with O-phosphorylethanolamine as initiator. MG-NCA $(1.0 \mathrm{~g})$ was dissolved in ethyl acetate $(50 \mathrm{~mL}$; Katayama
Chemical Co., Ltd., Japan). The solution was added dropwise to aqueous solution ( $\mathrm{pH} 9.0$ ) containing the initiator and the mixture was vigorously stirred for two hours at room temperature. The mixture was evaporated at $60^{\circ} \mathrm{C}$ to give a white powder. The white powder was washed with water several times and dried in vacuo. Gel permeation chromatographic (GPC) analysis of the sample obtained was performed using a G $4000 \mathrm{HXL}$ column (Tosoh Ltd., Japan) and $N, N$-dimethylformamide as elution solvent. The highly-purified sample was confirmed by a single peak in the GPC trace. Average degree of polymerization, $n$, of $10\left(\mathrm{PMG}_{10}-\mathrm{P} ; M_{\mathrm{n}}=1571\right)$ was estimated from ${ }^{1} \mathrm{H}$ NMR analysis of trifluoroacetic acid solution of the polypeptide. The distribution of molecular weight $\left(\bar{M}_{\mathrm{w}} / \bar{M}_{\mathrm{n}}\right)$ of $\mathrm{PMG}_{10}-\mathrm{P}, 1.10$, was found by GPC analysis.

Aqueous solutions of $\mathrm{PMG}_{10}-\mathrm{P}$ for various measurements below were prepared by sonication with the probe type sonifier (Biomic model $7250 \mathrm{~B}$, SEIKO I\&E Co. Ltd., Japan) at $40 \mathrm{~W}$ and $0^{\circ} \mathrm{C}$ for $1-2 \mathrm{~min}$.

Circular Dichroism (CD) Spectroscopy

Circular dichroism (CD) spectra of $\mathrm{PMG}_{10}-\mathrm{P}$ in aque-<smiles></smiles>

Scheme 1. Chemical structure of the amphiphilic polypeptide $\left(\mathrm{PMG}_{\mathrm{n}}-\mathrm{P}\right)$. 
ous solution at several temperatures were recorded on a JASCO J-820 K equipped with temperature control system (PTC-423 L). CD spectra of the $\mathrm{PMG}_{10}-\mathrm{P}$ aqueous solution were expressed in terms of molar ellipticity, $[\theta]$, based on the residue molecular weight.

\section{Transmission Electron Microscopy (TEM)}

The morphology of the $\mathrm{PMG}_{10}-\mathrm{P}$ assembly in aqueous solution was observed by transmission electron microscopy (TEM) on a JEOL-100 CXII. Samples of TEM observation were prepared by applying a drop of $\mathrm{PMG}_{10}-\mathrm{P}$ aqueous solution $\left(6.4 \times 10^{-5} \mathrm{M}\right)$ onto carbon-coated 400 mesh copper grids, which were then negatively stained by the dropwise addition of $2 \%$ aqueous ammonium molybdate.

\section{Fourier Transform Infrared Spectroscopy (FT-IR)}

The FT-IR spectrum of $\mathrm{PMG}_{10}-\mathrm{P}$ cast film from the aqueous solution $\left(6.4 \times 10^{-5} \mathrm{M}\right)$ was measured by a Perkin-Elmer Spectrum 2000.

\section{Transmittance Measurements}

To estimate the aggregation of $\mathrm{PMG}_{10}-\mathrm{P}$ in aqueous solution, we measured the transmittance $(T \%)$ at 700 $\mathrm{nm}$ on spectrophotometer (JASCO, UVDEC-670). When the concentration of $\mathrm{PMG}_{10}-\mathrm{P}$ aqueous solution is high, the formation of an assembly induces decrease in transmittance owing to scattering of light in solution. Conversely, the transmittance of the $\mathrm{PMG}_{10}-\mathrm{P}$ aqueous solution was similar to that of pure solvent at low concentration in which the assembly did not form.

\section{Fluorescence Polarization Measurements}

Polarization, $P=\left(I_{/ /}-I_{\perp}\right) /\left(I_{/ /}+I_{\perp}\right)$, of diphenylhexatrien (DPH) in the $\mathrm{PMG}_{10}-\mathrm{P}$ assembly was determined with a fluorescence polarization spectrophotometer FS$501 \mathrm{~A}$ (Union Giken). $I_{/ /}$and $I_{\perp}$ are fluorescence intensities polarized parallel and perpendicularly to the direction of polarized excitation beam. The concentration of $\mathrm{PMG}_{10}-\mathrm{P}$ was $6.4 \times 10^{-5} \mathrm{M}$. The concentration of $\mathrm{DPH}$ was $3.4 \times 10^{-6} \mathrm{M}$. The excitation wavelength of $\mathrm{DPH}$ was $375 \mathrm{~nm}$, and fluorescence was observed at $430 \mathrm{~nm}$.

\section{Differential Scanning Calorimeter (DSC)}

The DSC curve was obtained for $\mathrm{PMG}_{10}-\mathrm{P}$ solution with a differential scattering calorimeter DSC 7 (Perkin -Elmer Co., Ltd., Japan). $60 \mu \mathrm{L}$ of aqueous solution of $\mathrm{PMG}_{10} \mathrm{P}\left(6.4 \times 10^{-5} \mathrm{M}\right)$ was sealed in a silver sample pan. The pan was placed in the DSC cell compartment and cooled to $c a .0^{\circ} \mathrm{C}$. Measurements were started from $10^{\circ} \mathrm{C}$, and temperature rose at a rate of $5^{\circ} \mathrm{C} \min ^{-1}$ up to $50^{\circ} \mathrm{C}$.

\section{RESULTS AND DISCUSSION}

\section{Secondary Structure of PMG10-P in Aqueous Solution}

To confirm the conformation of $\mathrm{PMG}_{10} \mathrm{P}$ in aqueous solution, $\mathrm{CD}$ spectra of $\mathrm{PMG}_{10}-\mathrm{P}$ were obtained at room temperature (Figure 1). The CD spectra were strongly dependent on $\mathrm{PMG}_{10}-\mathrm{P}$ concentration. The $\mathrm{CD}$ spectrum of $\mathrm{PMG}_{10} \mathrm{P}$ at $1.0 \times 10^{-4} \mathrm{M}$ (Figure 1a) exhibited a positive band at $198 \mathrm{~nm}$ and negative band at $218 \mathrm{~nm}$, respectively, indicating the polypeptide to be in the $\beta$-form

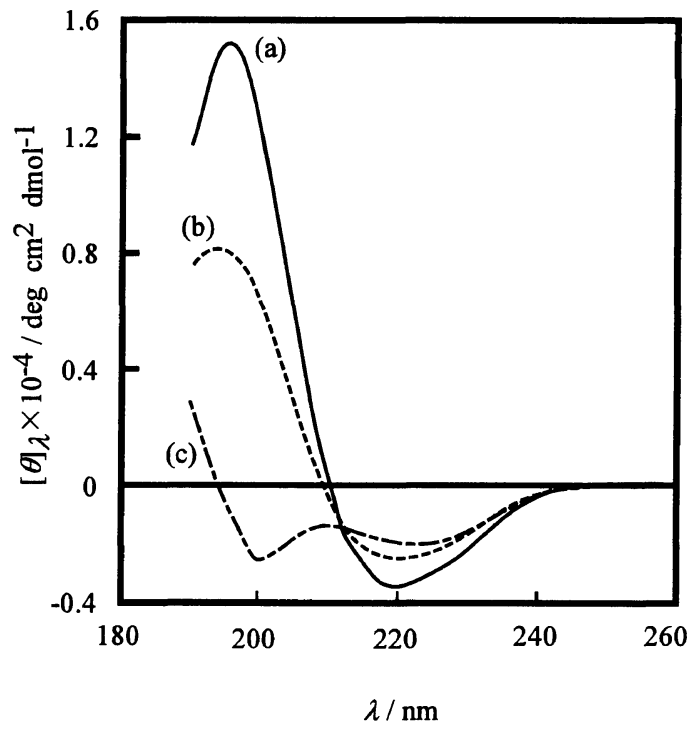

Figure 1. CD spectra of $\mathrm{PMG}_{10}-\mathrm{P}$ in aqueous solution. Concentration of $\mathrm{PMG}_{10} \mathrm{P}$ (a) $1.0 \times 10^{-4} \mathrm{M}$, (b) $3.0 \times 10^{-5} \mathrm{M}$, and (c) $1.0 \times$ $10^{-5} \mathrm{M}$.

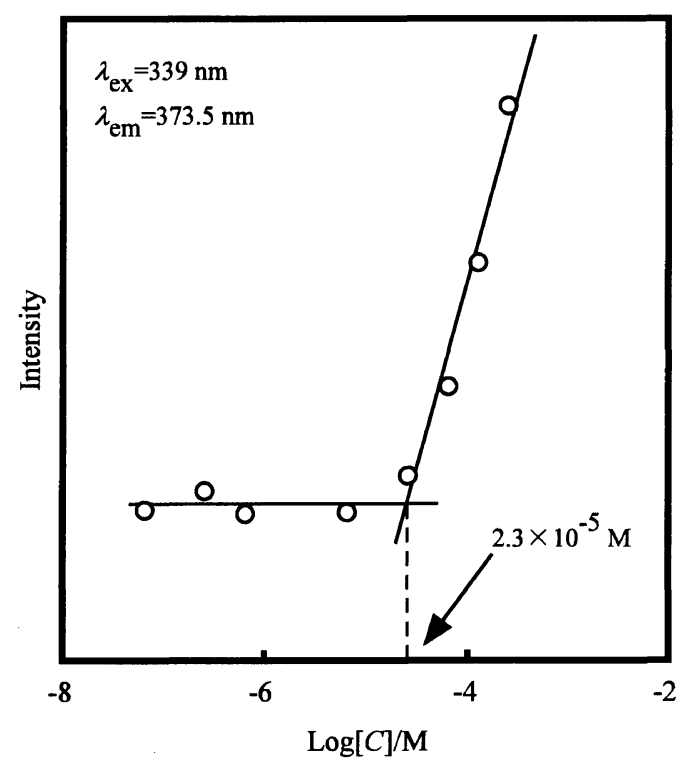

Figure 2. Plots of fluorescence intensity of pyrene as a function of the concentration of $\mathrm{PMG}_{10}-\mathrm{P}$.

conformation at $1.0 \times 10^{-4} \mathrm{M}$. At $\mathrm{PMG}_{10}-\mathrm{P}$ of $1.0 \times 10^{-5}$ $M$ the spectrum (Figure 1c) showed a CD pattern indicating the polypeptide to consist of random coil with same $\alpha$-helix structure. The CD spectrum at $3.0 \times 10^{-5}$ $\mathrm{M}$ (Figure 1b) was between the spectra of Figure 1a and 1c. The amphiphilic polypeptide, $\mathrm{PMG}_{10}-\mathrm{P}$, had a critical aggregate concentration (CAC) similar to other amphiphiles. We used fluorescence ${ }^{26}$ with pyrene as probe for CAC determination, as a result, $\mathrm{CAC}$ of $\mathrm{PMG}_{10}-\mathrm{P}$ was estimated to be $2.3 \times 10^{-5} \mathrm{M}$ by the concentration dependence of the fluorescence intensity of pyrene in the aqueous system (Figure 2). At $1.0 \times 10^{-4} \mathrm{M}$ above CAC, $\mathrm{PMG}_{10} \mathrm{P}$ aggregates. This intermolecular interaction may induce $\beta$-sheet conformation (Figure 1a). $\mathrm{PMG}_{10}-\mathrm{P}$ dispersed individually at $1.0 \times 10^{-5} \mathrm{M}$ below the CAC to exist in the random coil rich conformation (Figure 1c). 

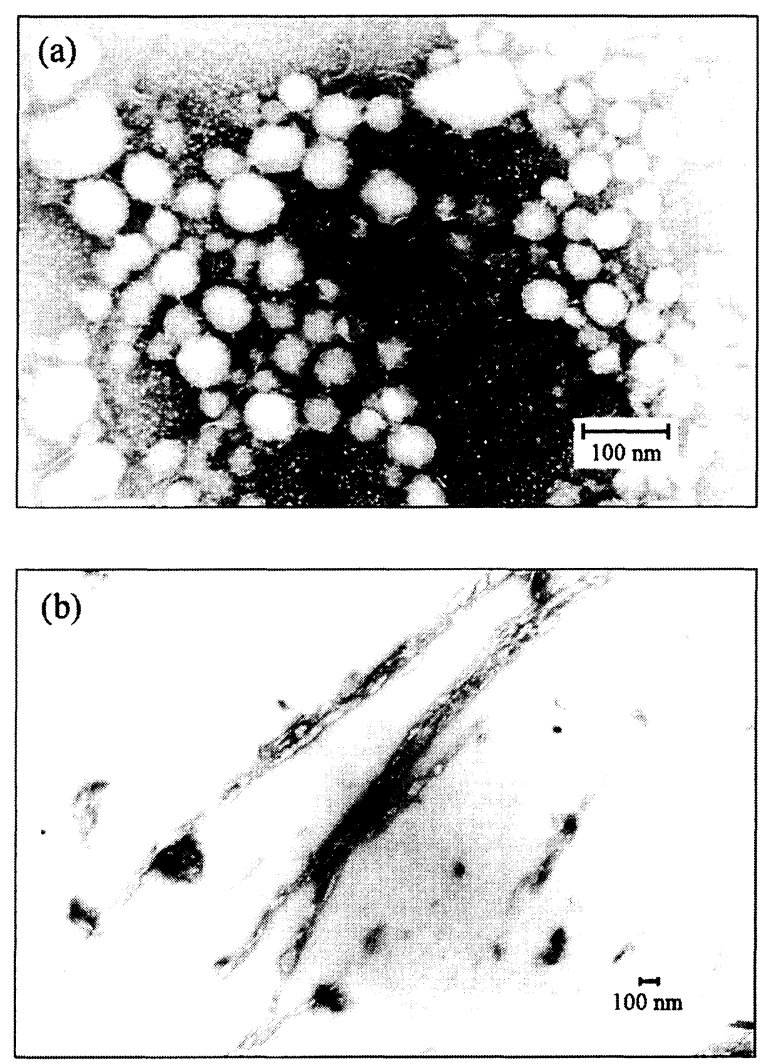

Figure 3. Transmission electron microscopy of $\mathrm{PMG}_{10} \mathrm{P}$ assembly in aqueous solution (a) after sonication and (b) aging $1 \mathrm{~h}$.

Just above CAC, $3.0 \times 10^{-5} \mathrm{M}$, the $\beta$-sheet aggregate coexist with the molecularly dispersed $\mathrm{PMG}_{10} \mathrm{P}$ in random coil conformation and the contribution of both conformations to the CD spectrum is roughly equivalent owing to same concentration. This is the reason why the spectrum of Figure $1 \mathrm{~b}$ is located between the spectra of Figure $1 \mathrm{a}$ and $1 \mathrm{c}$.

\section{Molecular Assembly of $P M G_{10}-P$ in Aqueous Solution}

$\mathrm{PMG}_{10}-\mathrm{P}$ was soluble in aqueous solution and formed $\beta$-sheet assembly above CAC $\left(6.4 \times 10^{-5} \mathrm{M}\right)$. We observed directly the morphology of this molecular assembly by transmission electron microscopy (TEM). $\mathrm{PMG}_{10^{-}}$ $\mathrm{P}$ dissolved in water by sonication to form globular assemblies with diameter of 50-100 nm (Figure 3a). At $1 \mathrm{~h}$, the globular assemblies joined to transform fibrous aggregates (Figure $3 \mathrm{~b}$ ). The fibrils assembled to form twisted ribbon-like aggregates as shown elsewhere. ${ }^{24}$ Morphological changes of the aggregates are shown in Figure 4 . The thickness of the ribbon-like sheet in Figure 4 was estimated to be $c a .4 .0 \mathrm{~nm} .{ }^{24}$ This assembly may form by monolayer in water, because the thickness of the ribbon-like sheet was too close to chain length ( $c a$. $3.9 \mathrm{~nm}$ ) of $\mathrm{PMG}_{10}-\mathrm{P}$ when in the $\beta$-form conformation.

To confirm the conformation of $\mathrm{PMG}_{10}-\mathrm{P}$ assembly, the FT-IR spectrum of $\mathrm{PMG}_{10} \mathrm{P}$ cast film from aqueous solution $\left(6.4 \times 10^{-5} \mathrm{M}\right)$ was measured (Figure 5$)$. The spectrum exhibited bands at 1624 and $1689 \mathrm{~cm}^{-1}$ (Amide I) and $1530 \mathrm{~cm}^{-1}$ (Amide II), typical for anti-parallel $\beta$ sheet conformation. Thus, $\mathrm{PMG}_{10}-\mathrm{P}$ was soluble in aqueous solution to form ribbon-like assemblies having highly ordered interiors as shown by the structural globular assembly
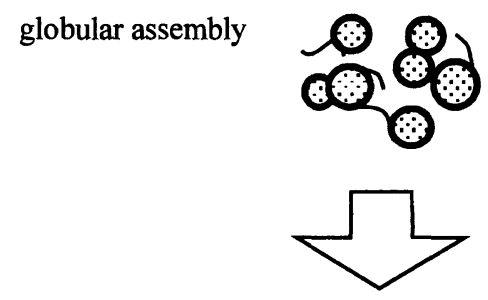

fibrous aggregate
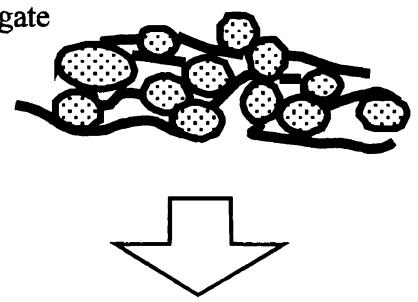

ribbon-like assembly

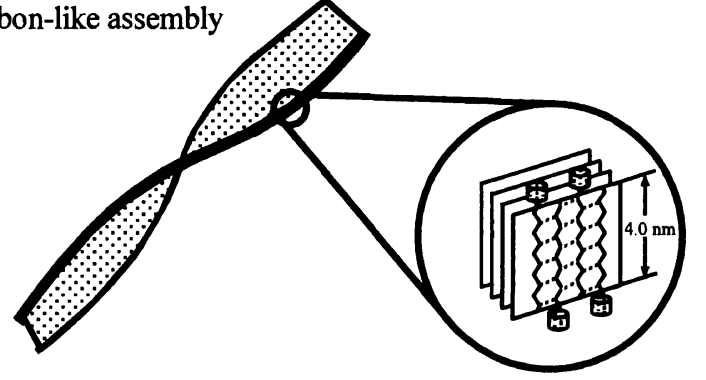

Figure 4. Schematic illustration of an aggregate of $P \mathrm{MG}_{10}-\mathrm{P}$ in aqueous solution. ${ }^{24}$

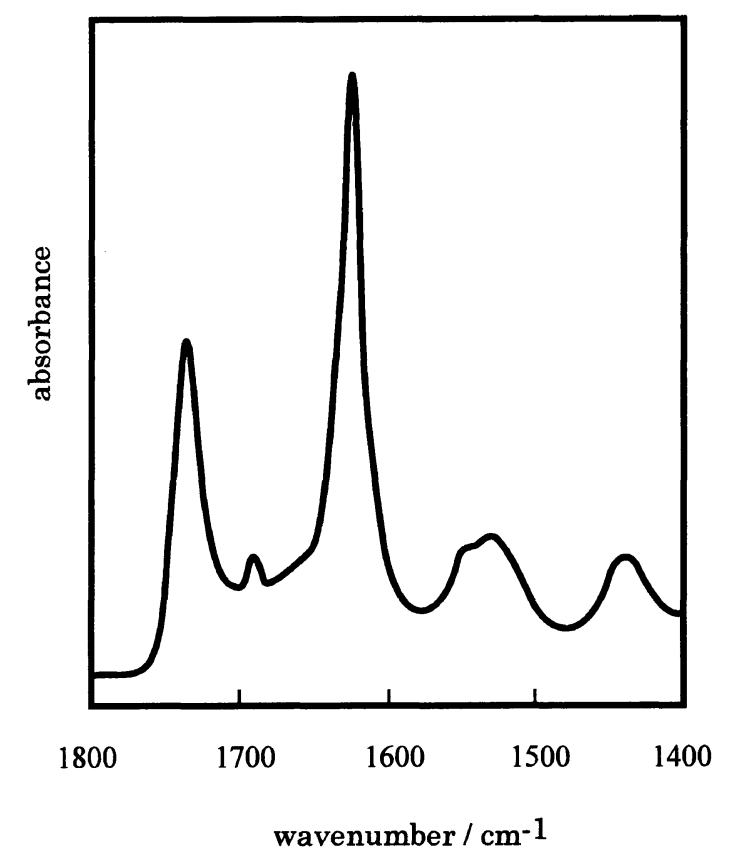

Figure 5. FT-IR spectrum of $\mathrm{PMG}_{10}-\mathrm{P}$ cast film from aqueous solution.

model in Figure 4.

\section{Temperature-Concentration Diagram}

To estimate the temperature dependence of the polypeptide conformation, we measured the CD spectra of $\mathrm{PMG}_{10} \mathrm{P}$ in aqueous solution $\left(1 \times 10^{-4} \mathrm{M}\right)$ at several temperatures (Figure 6). At $25^{\circ} \mathrm{C}$, the spectrum of 


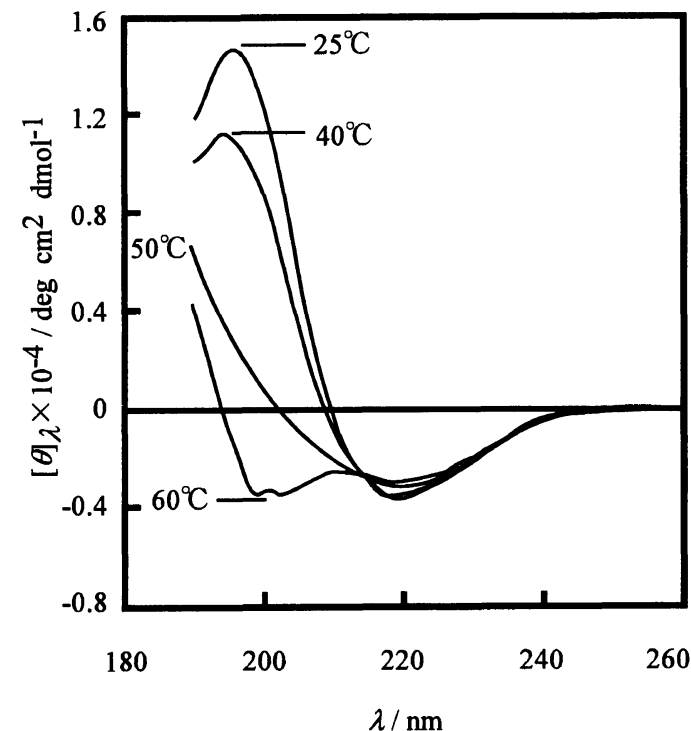

Figure 6. Temperature dependence of $\mathrm{CD}$ spectra of $\mathrm{PMG}_{10}-\mathrm{P}$ in aqueous solution. $\left[\mathrm{PMG}_{10}-\mathrm{P}\right]=1.0 \times 10^{-4} \mathrm{M}$.

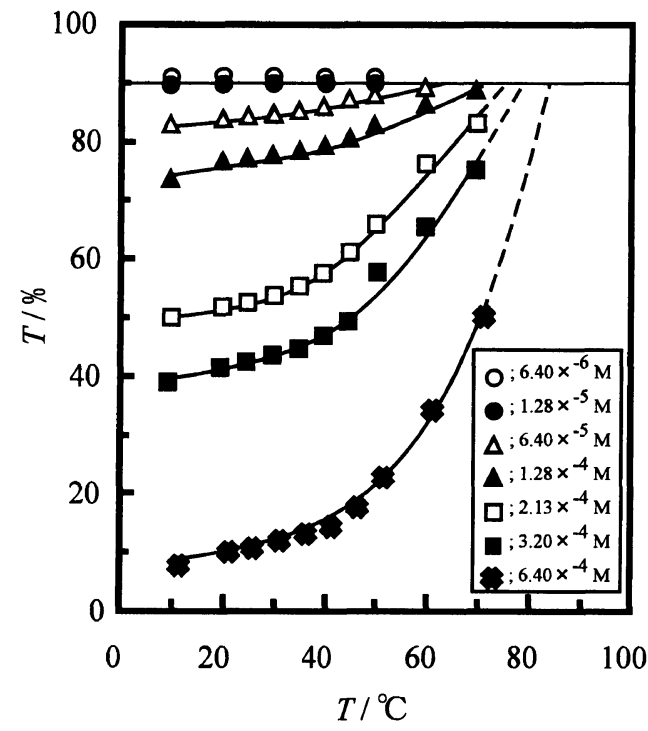

Figure 7. Temperature dependence of transmittance at $700 \mathrm{~nm}$ of $\mathrm{PMG}_{10}-\mathrm{P}$ in aqueous solution at various concentrations.

$\mathrm{PMG}_{10}-\mathrm{P}$ exhibited a positive band at $198 \mathrm{~nm}$ and negative band at $218 \mathrm{~nm}$ typical of $\beta$-sheet conformation. As the temperature increased, is thus $[\theta]_{198}$ gradually decreased. The $\beta$-sheet conformation transformed to random coil and $\alpha$-helix mixed conformation. This indicates the disaggregation of $\mathrm{PMG}_{10}-\mathrm{P}$ ribbon-like sheet by increasing the temperature. We confirmed this by temperature dependence of transmittance (Figure 7). At the $\mathrm{PMG}_{10}-\mathrm{P}$ concentration below $\mathrm{CAC}, 6.40 \times 10^{-6}$ and 1.28 $\times 10^{-5} \mathrm{M}$, the transmittance of aqueous solution, $c a$. $90 \%$, was almost the same as that of pure water from $10^{\circ} \mathrm{C}$ to $50^{\circ} \mathrm{C}$, reflecting the molecularly dispersed $\mathrm{PMG}_{10}-\mathrm{P}$. Above CAC, the transmittance of aqueous $\mathrm{PMG}_{10}-\mathrm{P}$ solutions was low at room temperature but increased with temperature owing to disaggregation of the polypeptide above a certain temperature depending on concentration. This temperature was defined as the ag-

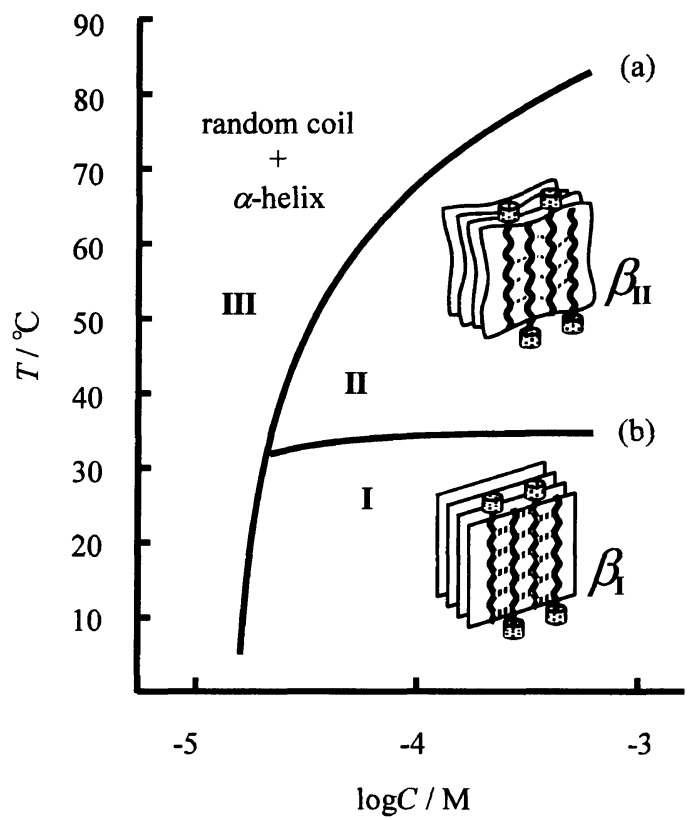

Figure 8. Temperature-concentration phase diagram for $\mathrm{PMG}_{10^{-}}$ $\mathrm{P}$ in aqueous solution.

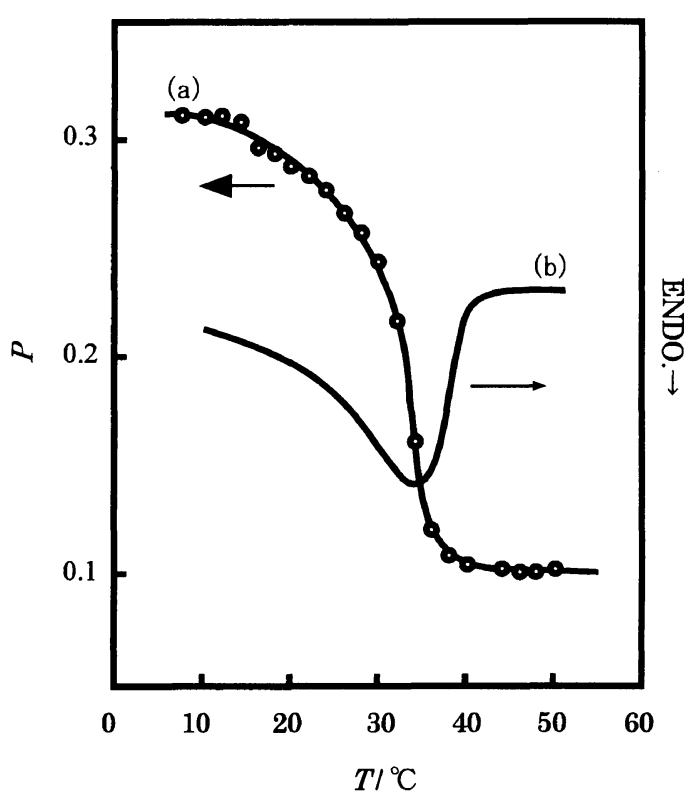

Figure 9. (a) Temperature dependence of degree of polarization, $\mathrm{P}$, of $\mathrm{DPH}$ in $\mathrm{PMG}_{10} \mathrm{P}$ aqueous solution. $\left[\mathrm{PMG}_{10} \mathrm{P}\right]=6.4 \times 10^{-5} \mathrm{M}$. $[\mathrm{DPH}]=3.4 \times 10^{-6} \mathrm{M}$. (b) DSC curve of $\mathrm{PMG}_{10}-\mathrm{P}$ aqueous solution. $\left[\mathrm{PMG}_{10} \mathrm{P}\right]=6.4 \times 10^{-5} \mathrm{M}$.

gregation to desaggregation temperature where the transmittance of each concentration is $90 \%$ of molecularly dispersed solution. At higher concentrations this temperature was found by extrapolating the temperature dependence curve to $90 \%$ transmittance as shown in Figure 7. From these results we got the line (a) in the temperature-concentration diagram in Figure 8.

To investigate the structure of the $\mathrm{PMG}_{10}-\mathrm{P}$ assembly in more detail the temperature dependence of fluorescence polarization, $\mathrm{P}$, of $\mathrm{DPH}$ in the assembly was observed (Figure 9a). P of DPH reflects the microscopic viscosity of a molecular aggregate. Fluorescence polariza- 
tion exhibits remarkable temperature dependence. $\mathrm{P}$ of DPH embedded in the assembly was ca. 0.3 at low temperature and gradually decreased with temperature rise up to $\mathrm{ca} .34^{\circ} \mathrm{C}$. It decreased drastically around $34^{\circ} \mathrm{C}$ to 0.1 at high temperature. This indicates that the interior of the aggregate is rigid at low temperature and large structure change occurred around $34^{\circ} \mathrm{C}$. The DSC curve of $\mathrm{PMG}_{10}-\mathrm{P}$ aqueous solution is shown in Figure $9 \mathrm{~b}$. The endothermic peak supports that a first order phase transition of the aggregate occurs at $T_{\mathrm{c}}=34^{\circ} \mathrm{C}$ which corresponds to the temperature observed as large decrease in florescence polarization (Figure 9a). These results show the $\beta_{\text {I }}$ to $\beta_{\text {II }}$ phase transition similar to bilayer systems, even though the molecular assembly is composed of polypeptide amphiphiles without hydrocarbon chains. From peak area, transition enthalpy was estimated as ca. $10 \mathrm{~kJ} /$ residue mol. This value is in the range of hydrogen-bond strength. The phase transition may thus be attributed to deformation of intermolecular hydrogen bonding between polypeptide molecules in the $\beta$-sheet aggregate. From DSC measurements at several $\mathrm{PMG}_{10^{-}}$ $\mathrm{P}$ concentrations we got the line $(\mathrm{b})$ in Figure 8. A temperature-concentration diagram for aqueous $\mathrm{PMG}_{10^{-}}$ $\mathrm{P}$ solution was obtained. The $\mathrm{PMG}_{10}-\mathrm{P}$ molecule was isolated in solution as a random coil rich conformation in low concentration and high temperature (region III). In region $\beta_{\mathrm{I}}, \mathrm{PMG}_{10}-\mathrm{P}$ molecules spontaneously aggregate to form a ribbon-like sheet structure. The interior of the assembly was well-defined and rigid structure based on the $\beta$-sheet conformation. The $\mathrm{PMG}_{10}-\mathrm{P}$ aggregate took on a fluid interior above $c a .35^{\circ} \mathrm{C}$ in the region $\beta_{\mathrm{II}}$.

\section{CONCLUSION}

The amphiphilic polypeptide, poly ( $\gamma$-methyl L-glutamate) with a phosphate moiety at the terminal, was soluble in water and spontaneously assembled to form ribbon-like molecular aggregates, above CAC, each composed of an anti-parallel $\beta$-sheet structure. The assembly formation is closely related to the conformation of $\mathrm{PMG}_{10}-\mathrm{P}$, which depends on concentration and temperature of aqueous solution. $\mathrm{PMG}_{10}-\mathrm{P}$ forms a unique aggregate having well-defined interior and characteristics such as self-organization and thermal transition similar to the lipid bilayer.

Acknowledgment. This study was partly supported by New Energy and Industrial Technology Development Organization (NEDO) for Technology in Material Struc- ture Control.

\section{REFERENCES}

1. B. Alberts, D. Bray, J. Lewis, M. Raff, K. Roberts, and J. D. Watson, in "Molecular Biology of The Cell," 3rd ed, Garland Publishing, Inc., New York \& London, 1994, chapter 11.

2. J. N. Israelachvili, D. J. Mitchell, and B. W. Ninham, J. Chem. Soc., Faraday Trans. 2, 1525 (1976).

3. T. Kunitake and Y.Okahata, J. Am. Chem. Soc., 99, 3860 (1977).

4. T. Kunitake, Angew. Chem., Int. Ed., Engl., 31, 709 (1992).

5. J. H. Fuhrhop, D. Spiroski, and C. Boettcher, J. Am. Chem. Soc., 115, 1600 (1993).

6. S. Munoz, J. Mallen, A. Nakano, Z. Chen, I. Gay, L. Echegoyen, and G. W. Gokel, J. Am. Chem. Soc., 115, 1705 (1993).

7. N. Kimizuka, T. Kawasaki, K. Hirata, and T. Kunitake, $J$. Am. Chem. Soc., 115, 4387 (1993).

8. H. Kuwahara, M. Hamada, Y. Ishikawa, and T. Kunitake, J. Am. Chem. Soc., 115, 3002 (1993).

9. D. S. Hudson, H. T. Jung, V. Percec, W. D. Cho, G. Johansson, G. Ungar, and V. K. S. Balagurusamy, Science, 17, 449 (1997).

10. N. Yamada, K. Matsubara, E. Koyama, and M. Fujioka Chem. Lett., 1033 (1997).

11. N. Kimizuka, T. Kawasaki, K. Hirata, and T. Kunitake, J. Am. Chem. Soc., 120, 4094 (1998).

12. M. P. Pileni, Supramolecular Science, 5, 321 (1998).

13. S. Svenson and B. P. Messersmith, Langmuir, 15, 4464 (1999).

14. K. Yamada, H. Ihara, T. Ide, T. Fukumoto, and C. Hirayama, Chem. Lett., 1713 (1984).

15. N. Nakashima, S. Asakuma, and T. Kunitake, J. Am. Chem. Soc., 107, 509 (1985).

16. T. Imae, Y. Takahashi, and H. Muramatsu, J. Am. Chem. Soc., 114, 3414 (1992).

17. T. Imae, Y. Ikeda, M. Iida, N. Koine, and S. Kaizaki, Langmuir, 14, 5631 (1998).

18. A. Toyotama, S. Kugimiya, M. Yonese, T. Kinoshita, and Y. Tsujita, Chem. Lett., 443 (1997).

19. H. Hosokawa, T. Kinoshita, Y. Tsujita, and H. Yoshimizu, Chem. Lett, 745 (1997).

20. K. Kishihara, T. Kinoshita, T. Mori, and Y. Okahata, Chem. Lett., 951 (1998).

21. K. Fujita, S. Kimura, and Y. Imanishi, Langmuir, 15, 4377 (1999).

22. T. Kinoshita, T. Doi, A. Kato, H. Hosokawa, Y. Tsụjita, and H. Yoshimizu, Chaos, 9, 276 (1999).

23. S. Kimura, D.-H. Kim, J. Sugiyama, and Y. Imanishi, Langmuir, 15, 4461 (1999).

24. T. Doi, T. Kinoshita, H. Kamiya, Y. Tsujita, and H. Yoshimizu, Chem. Lett., 262 (2000).

25. T. Doi, T. Kinoshita, Y. Tsujita, and H. Yoshimizu, Seni Gakkaishi, 56, 221 (2000).

26. M. Wilhelm, C.-L. Zhao, Y. Wang, R. Xu, and M. A. Winnik, Macromolecules, 24, 1033 (1991). 